\title{
The Conceptual Framework of Postmodernism
}

İsmail DURSUNOĞLU *

* Bayburt Üniversitesi E-mail: iso_34_@hotmail.com

Copyright (C) 2015 İsmail DURSUNOĞLU. This is an open access article distributed under the Eurasian Academy of Sciences License, which permits unrestricted use, distribution, and reproduction in any medium, provided the original work is properly cited.

\begin{abstract}
Mankind, has experienced a lot of experience from traditional society that is dominated by religious and metaphysical narratives to modern society that absolutization of the mind for perceive the world and after the post-modern society that modernism questioned. Modernism that only real, scientific knowledge, objectivity and universality concept is modified by postmodernism. Postmodernism, have brought a new perspective for individuals in cultural, social, economic and political areas. Elements of the terms of this new perspective are pluralism, freedom, diversity, heterogeneous structures, localities. In this study, tackles the theoretical framework of the concept of postmodernism starting from of modern even the premodern period basic approach. The aim of this study is handle the concept of postmodernism that is much discussed today to the contrast of modernism and main points. Thus, the concept aims to be easily understood and interpreted.
\end{abstract}

Keywords: Modernism, Postmodernism, Enlightenment, Pluralism

\section{Kavramsal Çerçevede Postmodernizm}

\section{ÖZET}

İnsanoğlu, dinsel ve metafiziksel anlatıların hakim olduğu geleneksel toplumlardan, dünyayı algılamada aklın mutlaklaştırıldığı modern toplumlara ve sonrasında modernizmin sorgulandığı postmodern toplumlara kadar birçok tecrübe yaşamıştır. Modernizmin tek gerçek, bilimsel bilgi, nesnellik ve evrensellik kavramları postmodernizm ile değişime uğramıştır. Postmodernizm, kültürel, sosyal, ekonomik ve siyasal alanlarda, bireylere yeni bir bakış açısı getirmiştir. Çoğulculuk, özgürlük, farklılık, heterojen yapı, yerellik gibi unsurlar bu yeni bakış açısının öğeleridir. Bu çalışma, modern hatta pre-modern dönemin temel yaklaşımından yola çıkarak Postmodernizm kavramının teorik çerçevesini ele almaktadır. Çalışmanın amacı, günümüzde fazlaca tartışılan, postmodernizm kavramını, modernizm karşıtlığında ve temel noktaları ile ele almaktır. Böylece kavramın, kolayca anlaşılması ve anlamlandırılması hedeflenmektedir.

Anahtar Kelimeler: Modernizm, Postmodernizm, Aydınlanma, Çoğulculuk

\section{Giriş}

Aydınlanma öncesindeki geleneksel toplumlara bakıldığında, düşünsel ve toplumsal sistemlerin, dini ve metafiziksel öğeler tarafından biçimlendirildiği görülmektedir. Bu toplumlarda doğa, toplum ve insana ilişkin gelişmelerin kaynağında Tanrı iradesi yer almaktadır. (Akça, 2005a, 233)Toplumsal yap1 olarak feodal sistemin yaygın ve geçerli olduğu bu toplumlarda, siyasi ve dini kurumları sorgulamak pek mümkün değildir. Avrupa halklarının yaşam biçiminin, dinsel kurumların vesayeti 
altında olduğu bu dönemde, siyasi güç ve ekonomik yaşam da belli kişilerin elindedir. Dolayısıyla, geleneksel dönemde, belli bir kesimin toplum üzerinde egemenlik kurması oldukça kolaydır. (Bobaroğlu, 2002, 18)

Geleneksel toplum, modern algıdan uzak, sanayileşmemiş ve teknolojik altyapısı zayıf olan toplumları ifade eder. Zamanla batının yaşadığı Rönesans, Reform, burjuvazinin güçlenmesi, Aydınlanma, rasyonalist düşünce, Fransız İhtilali gibi değişim ve dönüşümler modernizme uzanan yolun önemli yapıtaşlarını oluşturmuştur. Bu gelişmeler, Batının geleneksel toplum değerlerinden sıyrılarak, yeni bir döneme, modern döneme, geçişine zemin hazırlamıştır.

\section{Modernleşme Dönemi}

Latince 'modernus' kelimesinde türetilen modern kavramı hemen şimdi, bugünkü, çağdaş, asri, anlamlarına gelir. İlk defa 5.yy da Hristiyan dünyasının o dönemini, Roma ve Pagan tarihinden ayırmak için kullanılmıştır. Modernleşme, bir aydınlanma projesi olarak ortaya çıkmış ve zamanla bazı gelişmeleri de bünyesine katarak günümüze kadar ulaşmıştır. (Tekeli, 1992, 5) Dinsel ve metafiziksel geleneklerin aşılmasıyla modern toplumlar, bilimsel nesnellik evrensellik, akılcılık gibi değerler üzerine kurulmuştur. Kapitalizm, sanayileşme, bilimsel ve teknolojik ilerlemeler, metalaşma, ulus devlet, modernizmin diğer öğeleridir. (Akça, 2005a, 233) Modernizme geçiş, akıl kavramına değer atfetmekle olmuştur. Doğanın nesnel kanunlar çerçevesinde işleyen bir mekanizma olduğundan hareketle, nesnel ve bilimsel yöntemi yücelten modern düşünce, bilimsel bilgi ve özgür birey konularına dikkat çekmiştir. (Akça, 2005b,)

Modernleşme oldukça farklı şekillerde tanımlanmaktadır. Ancak bütün tanımların öne çıkan ortak noktalar vardır. Modernleşme, geleneksel tarım ve küçük çaplı el sanatlarına dayalı üretimden sanayileşmiş, şehirleşmiş, okuryazarlık oranının arttığı, kitle iletişim araçları ve ulaşım olanaklarının geliştiği bir süreçtir. Toplumda farklılaşma ve uzmanlaşmay1 beraberinde getiren modernleşme, toplumun, geleneksel değerlerinden soyutlanıp yeniden tasarlanmasını gerekli görmektedir. (Aslan, 2001 s:94) Bir başka ifadeyle modernleşme, sanayileşme ve teknolojinin gelişmesi, toplumsal hayatta bilimsel bilginin önem kazanması, ticaretin yayılması, kırdan kente geçiş ile zihinsel kültürel ve yapısal değişikliği içeren bir kavramdır.

Modernizm, yeni bir dünya görüşü, kültürel gelişme ve yeni bir yaşam tarzını ifade eder. 1300'lü yıllara uzanan Rönesans dönüşümünün şekillendirdiği bir düşünce ve hayat tarzının egemen olduğu zaman dilimine modern dönem, bu dönemde ortaya çıkan ve özellikle 19. yy batı dünyasına hakim olan görüsşe modernizm, modern dönemdeki yaşam tarzına ise modernite denir. (Yıldırım 2010 s:705) Modernite, aydınlanma, rasyonalizm ve pozitivizm şeklinde üç ana temayı ön plana çıkarmıştır. Kant'a göre, aydınlanmanın gereği olarak bilgi ve inanç arasında bir ayrım yapmak gerekir. Bilginin kaynağ 1 dış dünya, bilgiyi elde etme yöntemi ise ampirizmdir. Aydınlanma özünde bir karşı çıkış hareketidir. Bu karşı çıkış, toplum üzerinde baskı kuran kurumlara, ortaçağın dinsel düşünce yapısına, geleneksel otorite, dogma ve geri kalmışlığa başkaldırıdır.

Modernizm, dünyanın akılsal tasarımıdır. Pozitivist bakış açısı nesnel gerçekliğin peşindedir. Kanaatlerden arınmış, gözlem ve deneye dayalı biçimde elde edilen bilgi geçerli bir bilgidir. $\mathrm{Bu}$ düşünce ise bütüncül açıklayıcı modellere kapı aralamaktadır. (Yıldırım 2010 s:707) Modernliğin birçok boyutu vardır. Bunlar, yönetim bilimi açısından pozitivizm, ekonomi açısından pazar, siyaset açısından ulus devlet, örgütlenme açısından ise bürokrasidir. Bütün bunların ortak noktası rasyonalizm ve ussallıktır. Modernliğin temel varsayımları, kapitalizm, endüstriyalizm, kentlilik, demokrasi, ussallık, bürokrasi, uzmanlaşma, farklılaşma, bilimsel bilgi ve ulus devlettir.

1400-1500 yılları arasında, batıda meydana gelen gelişmeler modernizme önemli katkılar sağlamıştır. İstanbul'un fethi ile beraber Uzakdoğu'yla iletişimi kopan Avrupa yeni yollar aramaya başlamış ve bunun başarıya ulaşmasıyla, sömürge zenginliği batıyı ekonomik olarak kalkındırmıştır. Matbaanın bulunması, Roma ve Yunan medeniyetini yeniden canlandırmış, okuryazar oranı yükselmiştir. Ticaret gelişmiş, şehirleşme büyümüştür. Bütün bu gelişmeler, aydınlanma felsefesine 
pozitif ivme kazandırmıştır. Ancak modernizm için bütün bunlardan daha önemli olan iki gelişme Fransız İhtilali ve Endüstri Devrimidir.

Hemen her düşünsel yapıda olduğu gibi modernizmin de zayıf noktaları söz konusudur. Bu düşünce sistemi birçok eleştiriyi de beraberinde getirmiştir. Özellikle postmodern söylemi siyasi literatüre kazandıracak olan modernliğin eleştirisi öncelikle aklın mutlaklaştırılmasına yöneliktir. Akıl kavramıyla doğayı hakimiyet altına alan insanoğlu sübjektif değerlerden arınmıştır. Geleneksel toplumdaki tanrı öğesi yerine akıl yerleştirilmiştir. Akıl tek gerçekçiliğin gereğidir. Modernizmin bu akılsal algısı zamanla eleştirilere sebep olmuştur. Farklılıklara karşı hoşgörünün zayıf olduğu, kültürel, dilsel ve bölgesel farklılıkları düzleştirici bir anlayışa sahip olan modernizm, taşıdığı bu değerler noktasında eleştirilerle karşılaşmaktadır. (Billig, 2003 s:151)

Yukarda bahsedildiği gibi, tanrı tekliği yerine aklın tekliğin getirilmesi, tekilci ve bütüncül düşünceden farklı olanın bilgisine ulaşamama problemini ortaya çıkarmıştır. Modernizmin bu tekçi anlayışı, toplumların özgün niteliklerinden kaynaklanan farkl1lık ve öznellikleri göz ardı etmektedir (Akça, 2005b,). Son olarak modernizmin etnosantrik yapısı bir diğer eleştiri noktası olmuştur. Farklılıkları, ötekileri, kendi değer yargılarına göre ele almak demokratik kültürün gelişmesine darbe vurmuştur (İlter, 2006) Bütün bu eksiklikler beraberinde yeni bir düşünce arayışlarını başlatmıştır. Postmodernizm bu arayışların neticesinde modernizme karşı, onu sorgulayan ve modern değerlerin aşılması için ortaya çıkarılmış bir düşünsel dönemdir.

\section{Postmodern Dönem}

Postmodernizm terimi, post(sonra) ve modern(çağdaş) kelimelerinin bir araya gelmesiyle oluşmuş ve modernizmin sonrası, ötesi anlamında kullanılmaktadır. Postmodernizm çıkış noktası, modernizmin sorgulanması hatta aşılması düşüncesine dayanır. Üzerinde tam bir konsensüs sağlanmamış olsa da postmodernizm başlangıçta felsefe, güzel sanatlar, edebiyat, mimari, gibi alanlarda ortaya çıkmış ve zamanla hayatın her evresinde kullanılır olmuştur. (Bayram, 37-39) Postmodernlik terimini ilk kullanan, tarihçi Arnold Toynbee'dir. 1974 yılında II. Dünya Savaşı sonrası batı dünyasının yeni dönemi için kullanmıştır. (Sarıbay 2001 s:6)

Postmodernizmi tanımlamak açısından iki olgu önemlidir. İlki Avrupa”nın, dünyanın diğer kesimleri üzerinde egemenlik hakkı olduğu yönündeki inancın son bulması, ikincisi yerel ve azınlık kültürlerine söz hakkı tanıyan medyanın gelişmesidir. $\mathrm{Bu}$ iki gelişme ile birlikte 18. ve 19. yy Avrupa'sında akıl ve ilerleme kavramlarına eşlik eden evrensellik söylemi önem kaybetmiş, bütüncül fikirler yerine çoğulculuk değer kazanmıştır.

Postmodernizm, modern düşünce ve kültüre ait temel unsurları sorgulayan ve rasyonalizm, evrensellik, Hristiyanlık gibi büyük anlatıları reddeden bir düşünce tarzıdır. Bu düşünce tarzı bazı kişiler için bir dönemi ifade eder. Söz konusu bu dönem Postmodern dönem olarak nitelendirilir. $\mathrm{Bu}$ kavram, yeni bir felsefi bakış, yeni bir söylem ve yeni bir üslubun adıdır. Genelde postmodernizm olarak adlandırılan düşünce ve pratiklerin tamamı II. Dünya Savaşından sonra ortaya çıktığı görülür. (Çağlar, 2008, 369-371) Bu düşünsel yapıyı ortaya çıkaran koşullar, batı insanının aydınlanmacı zihniyete, insanı makineleştiren yaşam biçimine, bilgiyi sadece deneye hasreden görüşlere duyulan güvensizliktir. (Bayram, 37-39) Modernizmin temel dayanaklarından olan pozitivizm, rasyonalizm ve determinizmi reddeden Postmodern anlayış, çoğulculuk, tarihilik, tabiata ve çevreye uyumu esas alır. (Ayy1ld1z 2005, 654)

Modern ve Postmodern kavramlarını iyi şekilde anlayabilmek için, 'gerçek' olgusuna nasıl baktıklarını incelemek gerekir. Modernite insan aklına aşırı derecede önem verir. Bu dönemin öne çıkan temel değerleri akıl ve akılcılıktır. Akıl, insanı değişmez, tek ve evrensel bir gerçeğe götürür. Postmodernizm ise tek ve mutlak bir gerçeğe karşı çıkmaktadır. Akla yönelik Postmodern eleştirinin belirleyicileri vardır. Modern akıl birlik, bütünlük, evrensellik, her yerde aynı kuralların geçerli olacağını öngörür. Postmodernizm ise aksine her durumun farklı olduğunu, dolayısıyla özel bir 
biçimde yorumlanması gerektiğini savunur. Modernizm de akıl, hükmedici, baskıc1 ve totaliter bir olgudur. Ayrıca akıl ve rasyonalite, postmodernizmin gerektirdiği duygu, içebakış, sezgi, özerklik, yaratıcılık ve hayal gücüne tamamıyla kapalıdır.

Modernizm tarafından savunulan doğa ve toplumsal düzen arasındaki zorunlu ilişki, toplumsal dünyanın nesnel yasalarca biçimlendirilmesi ve evrensel gerçeklik kavramları postmodernistler tarafından eleştirilmiştir. Postmodernistler her türlü bütünleştirici ve genelleştirici yaklaşımları reddeder. Çünkü bu düşünce egemen ifade ve anlamlara bir tepkidir. (Yıldırım, 2010, 711-712) Postmodernizm, bireyselleşme, cemaatleşme anlamında kullanılmakta ve modern düşünceye ait temel kavramların sorgulanması, tartışılması, hata reddini temel almaktadır (Çağlar, 2008, 370)

Tablo1: Modernizm ve Postmodernizmin karşılaştırılması

\begin{tabular}{|l|l|}
\hline \multicolumn{1}{|c|}{ Modernizm } & \multicolumn{1}{|c|}{ Postmodernizm } \\
\hline Tek ve mutlak gerçek & Birden çok gerçek(yorum) \\
\hline Doğaya hakimiyet & Doğayla ilişki \\
\hline Nesnellik & Öznellik \\
\hline Homojenlik & Heterojenlik \\
\hline Bütünlük & Farklılık \\
\hline Ulus-devlet güçlü & Ulus-devlet zayıf \\
\hline Etnisite kültür ve kimlik söylemi zayıf & Etnisite kültür ve kimlik söylemi güçlü \\
\hline Klasik yönetim ve bürokrasi & Değişen yönetim algısı \\
\hline
\end{tabular}

Postmodernistler, modern düşünce ve toplum anlayışını gerçekdışı ve mitsel buldukları için eleştirmişlerdir. Düşüncede ve toplumda çoğulculuğu esas alan bu düşünce sahipleri, bütünleştirici teorileri reddetmişler ve yorumu esas aldıkları için mutlak gerçeklik anlayışını sorgulamışlardır. Postmodernistler kültürel-kimliksel farklılıkları ve çeşitlilikleri kabul ederken, moderniteye özgü sınıf ve ulus gibi genelleyici kavramlara karşı çıkmışlardır. (Akça, 2005b) Postmodern teorisyenler, farklılık, çoğulculuk ve heterojenliğe vurgu yaparken, kimlik ve yerellik gibi konuları da gündeme taşımışlardır. Bu da, toplumlar bünyesinde, Radikal Demokrasi, Müzakereci Demokrasi gibi alternatif modelleri tartışılabilir kılmıştır. Ayrıca çok uluslu şirketlerin ön plana çıkması ve devlet egemenliğinin, bu kuruluşlarla birlikte yerel düzeyde STK'lar tarafınca paylaşıldığ bir döneme girilmiştir. Böylece klasik egemenlik anlayışında değişikliğe gidilmiştir. (Türköne, 2008, 502-503) Postmodern bir siyaset ve siyasi kültür, modern siyasi değerlerden, bürokrasiden, sadakat ve disiplinden, otoriteden, mekaniklikten uzaktır. Postmodernite ile özgürlük, heterojenlik ve farklılıklara değer kazandırılmıştır. Postmodern siyaset, liberal düşünce ve devlet anlayışı, katılımcılık, çoğulculuk ve farklılık değerlerini benimsemiş, sınırsız özgürlüklerin yaşandığı, buna paralel düşünce akımlarının desteklendiği, küreselleşen dünyada yeni bir siyasi kültür oluşturmuş̧tur. Azınlıkların varlığını pekiştiren, ulusalcılığı reddeden, etnik farklılıkları önemseyen, dil ve din gibi bütünleştirici öğelerden uzaklaşan postmodernler, liberal devlet anlayışının savunuculuğunu yapmışlardır. (Çağlar, 2008, 381384) 
Postmodernizm, kamu yönetimi anlayışında, merkeziyetçilikten uzaklaşan, yerellik, yerinden yönetim, yatay örgütlenme ve esnek uzmanlaşmayı esas alan bir düşünce biçimidir. Yurttaş yerine müşteri, tam istihdam yerine sözleşmeli çalışma, kurallara göre değerlendirme yerine performans değerlendirmesi diğer öne çıkan başlıklardır. (Yıldırım, 2010, 715) Postmodern düşüncenin öncülüğünü yapmış isimlerden bazıları Soren Kierkegaard, Karl Marx, Martin Heidegger, Friedrich Nietzsche, Edmund Husserl, Ludwing Wittgenstein'dir. Postmodern düşünürler arasında ise JeanFrançois Lyotard, Jean Baudrillard, Judith Butler, Helen Cixous, Gilles Deleuze, Luce Irigaray, Charles Jenks, Jesques Derrida, Michel Foucault, Julia Kristeva, Thomas S. Khun, Dietmar Kamper, Gianni Vattimo, Richard Rorty sayılabilir. (Çağlar, 2008, 373)

\section{Sonuç}

İnsanlığın ilk tarihinden itibaren toplumun bir öğesi olan birey, varlığını devam ettirmek için çevresiyle iletişim ve etkileşim içinde olmuştur. Az gelişmiş ve tarımsal üretimin hakim olduğu geleneksel toplumlarda insanları bir arada tutan temel değerler din ve metafiziksel unsurlardır. $\mathrm{Bu}$ dönemde, birey aklı tanrısal irade tarafindan baskı altında tutulmakta ve sistemin sorgulanmasına izin verilmemektedir. Zamanla Avrupa'da burjuvazinin gelişmesi, Rönesans, Reform, Fransız İhtilali ve özelikle Endüstri Devrimi ile birlikte aydınlanmanın önü açılmış ve insan hayatında tek ve mutlak geçerlilik olarak akıl ön plana çıkarılmıştır. Bu yeni dönem modernizm olarak adlandırılmıştır. Rasyonalite, nesnellik, pozitivizm yine bu dönemin en önemli unsurları haline gelmiştir. İnsan aklının mutlaklaştırılması ve bu şekilde dünyanın yeniden tasarlanması olan modern dönem bütüncül yaklaşımıyla farklılıkları yok ettiği, insanı metalaştırdığı, kişisel yorum neticesinde tek gerçekliğin mümkün olmadığı gibi eleştirilerle karşı karşıya kalmıştır. Modernizmin sorgulanması hatta aşılması yeni bir kavramı, Postmodernizmi, düşünsel gündeme taşımıştır.

Postmodernizm, modern dönemin, bütüncül, rasyonalist, mutlak akıl, determinizm gibi özelliklerini reddeder. Farklılık, çeşitlilik, heterojen yapı, yorumsal algı gibi kavramları ön plana çıkarır. Sanattan edebiyata, felsefeden siyasete kadar yaşamın her evresinde görülen postmodern akım II. Dünya Savaş1 sonrası ortaya çıkmıştır. Özellikle ulus-devlet anlayışını sorgulayan yerellik, çok uluslu şirketler, kültür, kimlik gibi öğeleri siyasi literatürde seslendirmesi bakımından önemli bir noktadadır. Postmodernizm, modernliğin mutlakıyeti yerine göreceliği referans alır. Modern ve postmodern dönem arasındaki en önemli fark akla yapılan vurgudur.

Postmodernizm sürekli değişen ve gelişen bir olgudur. Kavram öz itibariyle tanımlara, kesin yargılara ve tümsel yaklaşımlara karşıdır. Bazı çevrelerce modernizmin bir alternatifi olarak düşünülse bile aslında postmodernizm algılanabilir ve tanımlanabilir yeni bir kavram olmanın ötesindedir. Postmodernizm, en basit ifadeyle modernliğin sorgulanması ve modern yaşam biçiminin aşılması anlamına gelir.

\section{REFERENCES}

- Akça G., Postmodernite ve Ulus Devlet, AKÜ Sosyal Bilimler Dergisi, C:VII, S:2, Aralık, 2005a

- Akça G., Modernden Postmoderne Kültür ve Kimlik, Muğla Üniversitesi Sosyal Bilimler Dergisi, S:15 Güz 2005b

- Aslan S., Yılmaz Abdullah, Modernizme Bir Başkaldırı Projesi Olarak Postmodernizm, Cumhuriyet Üniversitesi İ̈BF Dergisi, C:2 S:2 2001

- Ayyıldız M., Edebiyat Bilgi ve Teorileri, Akçağ Yayınları, Ankara-2005

- Bayram Y., Postmodernizm(Modernizmin Ötesi), Baykara Dergisi, S:5 Sonbahar, Çorum

- Billig M., Banal Milliyetçilik, Çev: Cem Şişkolar, Gelenek Yayıncılık, İstanbul-2003

- Bobaroğlu M., Aydınlanma Sorunu ve Değerler, Ayna Yay. İstanbul-2002 
- Çağlar N., Postmodern Anlayışta Siyaset ve Kimlik, SDÜ İ̈BF Dergisi, Y:2008, C:13, $\mathrm{S}: 3$

- İlter T., Modernizm, Postmodernizm, Postkolonyalizm: Ben-Öteki İlişkileri ve Etnosantrizm, Küresel İletişim Dergisi, S:1 Bahar-2006

- Sarıbay A.Y., Postmodernite, Sivil Toplum ve İslam, Alfa Yayınları, İstanbul-2001

- Tekeli İ., Modernizm ve Postmodernizm Kavramları Üzerine, Hürriyet Gösteri S.E.D. No:138 Mayis-1992

- Türköne M., Siyaset, Lotus Yayınları, Ankara-2008

- Yıldırım M., Modernizm, Postmodernizm ve Kamu Yönetimi, Uluslararası İnsan Bilimleri Dergisi, C:7 S:1, 2010 